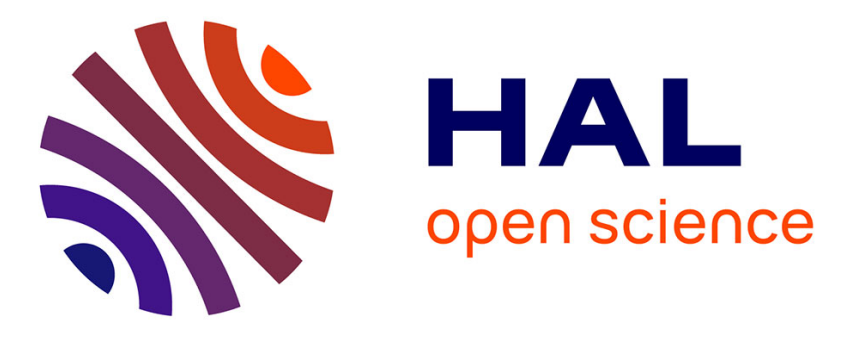

\title{
Regional climate modeling for the developing world: The ICTP RegCM3 and RegCNET
}

Jeremy Pal, Filippo Giorgi, Xunqiang Bi, Nellie Elguindi, Fabien Solmon, Xuejie Gao, Sara Rauscher, Raquel Francisco, Ashraf Zakey, Jonathan Winter, et al.

\section{To cite this version:}

Jeremy Pal, Filippo Giorgi, Xunqiang Bi, Nellie Elguindi, Fabien Solmon, et al.. Regional climate modeling for the developing world: The ICTP RegCM3 and RegCNET. Bulletin of the American Meteorological Society, 2007, 88 (9), pp.1395+. 10.1175/BAMS-88-9-1395 . hal-00342318

\section{HAL Id: hal-00342318 https://hal.science/hal-00342318}

Submitted on 30 Nov 2021

HAL is a multi-disciplinary open access archive for the deposit and dissemination of scientific research documents, whether they are published or not. The documents may come from teaching and research institutions in France or abroad, or from public or private research centers.
L'archive ouverte pluridisciplinaire HAL, est destinée au dépôt et à la diffusion de documents scientifiques de niveau recherche, publiés ou non, émanant des établissements d'enseignement et de recherche français ou étrangers, des laboratoires publics ou privés.

\section{(c)(1)}

Distributed under a Creative Commons Attribution| 4.0 International License 


\section{Regional Climate Modeling for the Developing World: The ICTP RegCM3 and RegCNET}

Jeremy S. Pal, Filippo Giorgi, Xunqiang Bi, Nellie Elguindi, Fabien Solmon, Xuejie Gao, Sara A. Rauscher, Raquel Francisco, Ashraf Zakey, Jonathan Winter, Moetasim Ashfaq, Faisal S. Syed, Jason L. Bell, Noah S. Diffenbaugh, Jagadish Karmacharya, Abourahamane Konaré, Daniel Martinez, Rosmeri P. da Rocha, Lisa C. Sloan, and Allison L. Steiner

Through modeling and international exchange, the Abdus Salam International Centre for Theoretical Physics is fostering advanced climate research in countries where scientific resources are often scarce.

P opulations in economically developing nations (EDNs) depend extensively on climate for their welfare (e.g., agriculture, water resources, power generation, industry) and likewise are vulnerable to variability in the climate system, whether due to anthropogenic forcing or natural processes. Furthermore, changes in atmospheric composition (e.g., greenhouse gases and aerosols) and land cover are likely to significantly alter regional climates (Nakicenovic et al. 2001), thereby affecting local socioeconomic development and livelihoods of EDN populations. Therefore, the evaluation of climate change and variability at seasonal-to-multidecadal time scales is of great benefit to these regions.

Climate models, both global and regional, are the primary tools that aid in our understanding of the many processes that govern the climate system. In the past, a lack of computational resources has hindered the use of climate models by EDN scientists. However, in the last decade the computing power of the common desktop personal computer $(\mathrm{PC})$ has dramatically increased 
and the costs of both PCs and data storage devices have correspondingly decreased, thereby allowing EDN scientists to locally run complex climate models. The expertise required to configure and run such models has thus become a greater limitation to their widespread use in EDNs.

The Abdus Salam International Centre for Theoretical Physics (ICTP) was established in the early 1960s with the mission to foster the growth of science in EDNs. Within this mission, the ICTP Earth System Physics (ESP) section has further developed a regional climate model (RCM) specifically designed to suit the needs of scientists working in EDNs. The importance of regional climate modeling for involving EDN scientists in climate research was recently highlighted by Huntingford and Gash (2005). The latest version of the ICTP RCM, named the ICTP Regional Climate Model version 3 (RegCM3), is the third generation of a modeling framework originally described in Giorgi and Bates (1989); and Dickinson et al. (1989; RegCM1), and later upgraded as described by Giorgi et al. (1993a,b; RegCM2) and Giorgi and Mearns (1999; RegCM2.5).

The ICTP ESP section maintains and distributes RegCM3 to a community of users worldwide, and the source code is freely available for research purposes. In order to meet the needs of this broad research community, RegCM3 has been designed to be user-friendly and highly portable to a variety of computer platforms. Compared to previous versions of the model, several improvements to the physics packages that enhance model performance in tropical and subtropical regions have been implemented.

AfFILIATIONS: PAL-Earth Systems Physics Group, The Abdus Salam International Centre for Theoretical Physics, Trieste, Italy, and Department of Civil Engineering and Environmental Science, Loyola Marymount University, Los Angeles, California; GIORGI, BI, Elguindi, Solmon, and Rauscher-Earth Systems Physics Group, The Abdus Salam International Centre for Theoretical Physics, Trieste, Italy; GAO-Earth Systems Physics Group. The Abdus Salam International Centre for Theoretical Physics, Trieste, Italy, and National Climate Center, Beijing, China; FrancIsCO-National Climate Center, Beijing, China; ZAKEY-Philippine Atmospheric Geophysical, and Astronomical Services Administration, Quezon City, Philippines; WINTER-Department of Air Pollution and Climate Change, Egyptian Meteorological Authority, Cairo, Egypt; AshfaQ-Global Change Impact Studies Centre and Pakistan Meteorological Department, Islamabad, Pakistan, and Purdue Climate Change Research Center, and Department of Earth and Atmospheric Sciences, West Lafayette, Indiana; SyEd AND SLOANGlobal Change Impact Studies Centre, and Pakistan Meteorological Department, Islamabad, Pakistan; BELL-Department of Earth Sciences, University of California, Santa Cruz, Santa Cruz,
In addition, the model can be interfaced with a wide range of large-scale boundary driving fields.

This community of RegCM3 users forms the basis of the ICTP-maintained Regional Climate Research Network (RegCNET). The overall purpose of RegCNET is to stimulate south-south and north-south scientific interactions on the topic of regional climate and impacts research and modeling, thereby helping to build and empower a community of scientists from EDNs. Here we define south-south as interactions between scientists in EDNs, and north-south as those between scientists in economically advanced nations (EANs; north) and EDNs (south). The network is built upon common research interests in regional climate variability, predictability, and change, and the associated impacts among scientists in both EANs and EDNs. Although RegCNET researchers do employ other models and methods, the use of a common tool, RegCM3, helps to increase and strengthen interactions within the network.

In the second section we describe the activities of RegCNET and then discuss its potential to build scientific capacity in the area of regional climate and impacts research. RegCM3, the main tool of RegCNET, is presented in the third section. We focus the discussion of RegCM3 on new developments in the model that have led to improved simulations over tropical and subtropical domains, thereby making the model a more usef ul tool for RegCNET scientists. Some illustrative results from these simulations are presented in the fourth section. Finally, a summary and future perspectives are presented.

California; Diffenbaugh-Purdue Climate Change Research Centre, and Department of Earth and Atmospheric Sciences, West Lafayette, Indiana; KarmaCHARYA-Department of Hydrology and Meteorology, Katmandu, Nepal; KonarÉ-Groupe Aérosols Pollution Laboratoire de Physique de L'Atmosphére, Université de Cocody, Abidjan, Ivory Coast; Martinez-Center for Atmospheric Physics, Institute of Meteorology, Havana, Cuba; DA RoCHAInstituto de Astronomia, Geofisica e Ciencias Atmosfericas, Universidade de São Paulo, São Paulo, Brazil; Steiner-Department of Environmental Science, University of California, Berkeley, Berkeley, California CORRESPONDING AUTHOR: Jeremy S. Pal, Strada Costiera, II, 34014 Trieste, Italy

E-mail:.jpal@alum.mit.edu 
DESCRIPTION OF ICTP RegCNET. RegCNET was inaugurated during the First ICTP Workshop on the Theory and Use of Regional Climate Models in June 2003. It has four primary activities to foster south-south and north-south scientific interactions on the topic of regional climate and impacts research, which are described below. Within the framework of RegCNET, scientists pursue regional climate research on a variety of topics, including regional climate change, prediction, and variability. RegCM3 is the primary tool used for this network; however, other tools are also used and encouraged, such as global models, observational datasets, and output from other model simulations. Recently, we broadened these topics to include some of the societal and ecological impacts of regional climate change and variability. The RegCNET Web site is maintained at users.ictp.it/RegCNET/. RegCNET performs the following functions.

Organize and host regular meetings at the ICTP. A main component of RegCNET is the organization and hosting of workshops on regional climate research. These workshops emphasize regional climate modeling and include lectures on the theory and applications of RCMs, as well as handson sessions on the use of RegCM3. Expert users, some of which are EDN participants from previous workshops, present and share their research, thereby allowing new participants to benefit from their experience. This provides an excellent opportunity for interaction with the greater scientific community. The First ICTP Workshop on the Theory and Use of Regional Climate Models, held June 2003, was attended by more than 70 participants from nearly 30 countries, mostly EDNs. In order to encourage broad participation among scientists from EDNs, ICTP supports travel to and local expenses at the workshops for EDN participants. The ICTP workshops also provide opportunities for the community to discuss the future directions of RegCNET, further developments of RegCM3, and general needs of the EDN participants. At our most recent workshop in June 2006, training was provided in the use of two crop and two hydrological models with RCM data. Information on upcoming ICTP regional climate research workshops may be found at users.ictp. it/RegCNET/activities.html.

Establish collaborative research projects. One of the main problems faced by EDN scientists is scientific isolation. To ameliorate this problem, a primary aim of RegCNET is the development of research projects designed and led by EDN scientists and to foster collaborations with experts in other countries. These collaborations typically include both south-south and north-south interactions. It is important to emphasize that the projects are designed and led by the EDN scientists, providing a greater sense of ownership and enthusiasm.

To help substantiate these collaborations, ICTP develops, maintains, and supports RegCM3, as well as a number of modeling and observational datasets. Scientific advice and supervision is provided to young scientists. In addition, the ICTP regular meetings provide forums to assess the progress of the projects, obtain feedback, and plan future activities.

An important measure of success is the publication of scientific results in internationally peer-reviewed journals. Collaborative research projects initiated at the June 2003 meeting resulted in the submission of 21 articles (18 accepted) to a special RegCNET issue of Theoretical and Applied Climatology involving nearly 40 authors from EDNs (Giorgi et al. 2006). Most of the papers were the direct result of collaborations between scientists in EDNs and EANs.

Support joint ICTP workshops in EDNs. The main goals of these workshops are to identify questions and problems of specific interest in regional climate research and to design and develop relevant collaborative projects. These workshops are also important for understanding and addressing local inf rastructural problems faced by the EDN scientists. Compared with the ICTP-hosted workshops having participation from around the world, local experts from the region are more involved in the educational aspects of these on-site workshops. For example, Pakistani scientists who attended the inaugural workshop in 2003 provided significant training at a joint Global Change Impact Studies Centre (GCISC)/ICTP workshop on regional climate modeling in Islamabad, Pakistan, in 2004.

The smaller size of these workshops allows for more targeted and individual attention to the participants and to their scientific and technical needs. As a result, these EDN-hosted workshops arouse a greater sense of ownership and enthusiasm in the collaborative effort. To date, such workshops have taken place in Islamabad, Pakistan (February 2004); Prague, Czech Republic (December 2004); Alexandria, Egypt (May 2005); Accra, Ghana (January 2006); and Gaborone, Botswana (February 2007).

Award ICTP-sponsored short-term research visits. These visits allow scientists working in EDNs to stay in 
residence at ICTP while working on independent and collaborative research projects, generally for a period of three to six months. These scientists have daily interactions with ICTP ESP scientists, as well as access to the ICTP inf rastructure. In addition, since many of the EDN members of RegCNET have multiple scientific responsibilities in their home countries (which in some cases include considerable non-climate-related activities), these sponsored visits provide an opportunity to devote undivided thought and effort to regional climate research. Examples of research performed during such visits include the improvement of the representation of convection, aerosols, and dust. Others have researched the impact of land cover changes and increased greenhouse gas concentrations on climate. Most recently researchers have investigated impacts of climate variability and change on water resources and crops. Information on applying for an ICTP-sponsored educational opportunity can be found at www.ictp.it/pages/ education.html.

Maintain the RegCNET e-mail list. Apart from the workshops, the primary forum for RegCNET interactions is an e-mail list (regcnet@lists.ictp.it). The list currently includes more than 250 members from both EDNs and EANs. Members discuss a variety of topics ranging from research ideas to project details. The interactions stimulated by the e-mail list give the community a greater sense of involvement, as well as encourage the progress of individual and collaborative research projects.

DESCRIPTION OF RegCM3. ICTP RegCM3 development encompasses efforts from a number of scientists worldwide. Some of the contributions were made by scientists from EDNs as a direct result of the RegCNET activities, such as the inclusion of the Massachusetts Institute of Technology (MIT) convection scheme and a dust module (see below). In this section, we first present a brief history of the RegCM system and then a description of new developments in RegCM3. The current release of RegCM3, as well as a beta version with features in testing, may be found at users.ictp.it/RegCNET/model.html.

RegCM history. Table 1 lists the various dynamical and physical packages of successive versions of the RegCM system. RegCM3 is an integration of the main improvements that have been made to version 2.5 (RegCM2.5) as described in Giorgi and Mearns (1999). These improvements are in the representation of precipitation physics, surface physics, atmospheric chemistry and aerosols, model input fields, and user interface. In addition, the model code has been modified for parallel computing. An important aspect of RegCM3 is that it is user-friendly and operates on a variety of computer platforms. To that end, substantial changes have been made to the preprocessing, running, and postprocessing

TABLE I. Description of the progression of the versions of the RegCM system.

\section{RegCMI}

Primary

references

Dynamics

Radiative transfer

Boundary layer

Land surface

Convective precipitation

Resolvable precipitation

Aerosols and chemistry

BATS la
Dickinson et al. (1989)

Giorgi and Bates (1989)

MM4

Anthes et al. (1987)

CCMI

Kiehl et al. (1987)

Local

Deardorff (1972)

Dickinson et al. (1986)

Anthes-Kuo

Anthes (1977)

Implicit

Giorgi and Bates (1989)

Not available
RegCM2

Giorgi et al. (1993a,b)

MM5 (hydrostatic)

Grell et al. (1994)

CCM 2

Briegleb (1992)

Nonlocal, counter-gradient Holtslag et al. (1990)

BATS le

Dickinson et al. (1993)

Grell (1993)

Anthes (1977)

Explicit

Hsie et al. (1984)

Not available

\section{RegCM2.5}

Giorgi and Shields (1999)

Pal et al. (2000)

MM5 (hydrostatic)

Grell et al. (1994)

CCM3

Kiehl et al. (1996)

Nonlocal, counter gradient

Holtslag et al. (1990)

BATS le

Dickinson et al. (1993)

Zhang and MacFarlane

(1995)

Grell (1993)

SIMEX

Giorgi and Shields (1999)

Qian and Giorgi (1999)

(no dusts)

\section{RegCM3}

MM5 (hydrostatic)

Grell et al. (1994)

CCM3

Kiehl et al. (1996)

Nonlocal, counter gradient

Holtslag et al. (1990)

SUBBATS

Giorgi et al. (2003a)

MIT (Emanuel 1991)

Anthes-Kuo, Grell (1993)

SUBEX

Pal et al. (2000)

Solmon et al. (2006)

Zakey et al. (2006) 
of the model. Furthermore, RegCM3 has options to interface with a variety of reanalysis and GCM boundary conditions to provide a full suite of simulation options.

Dynamical core. Similar to RegCM versions 2 and 2.5 , the dynamical core of RegCM3 is based on the hydrostatic version of the fifth-generation Pennsylvania State University-National Center for Atmospheric Research (PSU-NCAR) Mesoscale Model (MM5; Grell et al. 1994). It is a primitive-equation, hydrostatic, compressible, sigma-vertical coordinate model. We refer the reader to the MM5 documentation (Grell et al. 1994) and articles describing the previous releases of the model (Giorgi and Shields 1999; Giorgi et al. 1993a) for more details.

Model physics. Many of the model physics packages in RegCM3 have been augmented since the release of RegCM2.5. These include the convective and nonconvective precipitation schemes, the land surface and ocean flux schemes, and atmospheric chemistry and aerosol modules. The radiative transfer package and planetary boundary layer scheme are still essentially unmodified, although small adjustments to some model parameters have been implemented.

Precipitation. The formation of precipitation in RegCM3 is represented in two forms: resolvable (or large scale) and convective (subgrid). The resolvable precipitation is generally associated with large-scale systems that move relatively slowly in the vertical direction, and is most common in the winter hemisphere. Conversely, convective precipitation typically occurs in the summer hemisphere and tropics at scales finer than $1 \mathrm{~km}$. Because of its fine scale, convective precipitation must be parameterized in most climate models.

In RegCM3, the resolvable-scale precipitation is represented using the subgrid explicit moisture (SUBEX) scheme (Pal et al. 2000). SUBEX accounts for the subgrid-scalevariability of clouds and includes formulations for the autoconversion of cloud water into rain water, the accretion of cloud droplets by falling raindrops, and the evaporation of falling raindrops. Cloud fractional cover is computed from the relative humidity, and clouds form when the relative humidity exceeds a certain threshold below grid cell saturation. In addition, the cloudliquid water threshold for the formation of rainfall is based on empirical in-cloud observations of cloud liquid water amounts. The implementation of this scheme has been shown to substantially improve the simulation of precipitation, temperature, and other cloud-related variables over the continental United States (Pal et al. 2000).

The parameterization of convective precipitation still remains one of the most important sources of errors in climate models. Three options are available in RegCM3 to represent cumulus convection: 1) the modified Anthes-Kuo scheme (Giorgi 1991; Anthes 1977); 2) the Grell scheme (Grell 1993); and 3) the MIT scheme (Emanuel and Zivkovic Rothman 1999; Emanuel 1991). The Anthes-Kuo and Grell schemes are well documented in articles describing results from the previous releases of the RegCM system (e.g., Giorgi et al. 1993b; Giorgi 1991).

The newest cumulus convection option to RegCM3 is the MIT scheme. Here we present a brief description of the scheme [more detailed descriptions can be found in Emanuel (1991) and Emanuel and Zivkovic Rothman (1999)]. The scheme assumes that the mixing in clouds is highly episodic and inhomogeneous (as opposed to a continuous entraining plume) and considers convective fluxes based on an idealized model of sub-cloud-scale updrafts and downdrafts. Convection is triggered when the level of neutral buoyancy is greater than the cloud-base level. Between these two levels, air is lifted and a fraction of the condensed moisture forms precipitation while the remaining fraction forms the cloud. The cloud is assumed to mix with the air from the environment according to a uniform spectrum of mixtures that ascend or descend to their respective levels of neutral buoyancy. The mixing entrainment and detrainment rates are functions of the vertical gradients of buoyancy in clouds. The fraction of the total cloud-base mass flux that mixes with its environment at each level is proportional to the undiluted buoyancy rate of change with altitude. The cloud-base upward mass flux is relaxed toward the sub-cloud layer quasiequilibrium.

In addition to a more physical representation of convection, the MIT scheme offers several advantages compared to the other RegCM3 convection options. For instance, it includes a formulation of the autoconversion of cloud water into precipitation inside cumulus clouds, and ice processes are accounted for by allowing the autoconversion threshold water content to be temperature dependent. Additionally, the precipitation is added to a single, hydrostatic, unsaturated downdraft that transports heat and water. Last, the MIT scheme considers the transport of passive tracers.

BIOSPHERE. Since RegCM2, the surface physics computations have been performed using BiosphereAtmosphere Transfer Scheme (BATS) version le 
(Dickinson et al. 1993), which describes the transfer of energy, mass, and momentum between the atmosphere and biosphere. In RegCM3, additional modifications have been made to BATS in order to account for the subgrid variability of topography and land cover using a mosaic-type approach (named SUBBATS; Giorgi et al. 2003b). This modification adopts a regular finescale surface subgrid for each coarse model grid cell. Meteorological variables are disaggregated from the coarse grid to the fine grid based on the topographic differences between the subgrid and coarse grid. The BATS calculations are then performed separately for each subgrid cell, and surface fluxes are reaggregated onto the coarse grid cell for input to the atmospheric model. This parameterization showed a marked improvement in the representation of the surface hydrological cycle in mountainous regions (Giorgi et al. 2003b).

WATER BODIES. In RegCM3, water bodies can be categorized as open (e.g., oceans) and enclosed (e.g., lakes). The air-sea energy fluxes from open bodies are computed from prescribed sea surface temperatures (SSTs) with no two-way interaction. That is, the ocean affects the atmosphere, but the atmosphere does not affect the ocean. The energy fluxes from enclosed water bodies can be computed using one of two methods: either a column lake model with two-way interaction (Hostetler and Bartlen 1990) or the prescribed SST method used for open bodies.

In RegCM3, there are two parameterization options for computing fluxes from open water bodies: the BATS formulation and the newly implemented Zeng scheme (Zeng et al. 1998). BATS uses standard Monin-Obukhov similarity relations to compute the fluxes with no special treatment of convective and very stable conditions. In addition, the roughness length is set to a constant; that is, it is not a function of wind and stability. For these reasons, according to Zeng et al. (1998), the ocean flux computations of BATS tend to overestimate evaporation in both high and low wind conditions. The Zeng scheme describes all stability conditions and includes a gustiness velocity to account for the additional flux induced by boundary layer scale variability. Tests by Francisco et al. (2006) show that RegCM3 coupled with the Zeng scheme better estimates evaporative fluxes over the South Pacific Ocean.

AtMOSPHERIC AEROSOLS AND CHEMISTRY. Atmospheric aerosols are known to have a substantial impact on the climate system, especially at regional scales. An aerosol scheme accounting for sulfate, organic carbon, and black carbon aerosols is incorporated in RegCM3 as described by Qian et al. (2001) and Solmon et al. (2006). Briefly, the scheme describes advection by atmospheric winds, diff usion by turbulence, vertical transport by deep cumulus convection, dry and wet removal processes, and gas and aqueous phase chemical conversion mechanisms. Wet removal both by resolvable- and subgrid-scale precipitation is parameterized as a function of the rate of conversion from cloud water to rain water and the hydrophilicity of the different aerosols. Surface dry deposition is calculated according to prescribed deposition velocities over land and water surfaces.

Both direct and indirect aerosol radiative ef fects are included in RegCM3 (Giorgi et al. 2003a). Direct radiative effects are accounted for by specifying the aerosol optical properties: extinction coefficient, single-scattering albedo, and an asymmetry parameter. Indirect effects are described by assuming that the effective cloud droplet radius depends on the aerosol mass concentration. This coupled aerosolchemistry model has been applied to the east Asia region (Giorgi et al. 2003a) and the Europe-Africa region (Solmon et al. 2006).

In addition, the coupling of a desert dust parameterization to the RegCM3 has recentlybeen completed (Zakey et al. 2006) using a scheme based primarily on the work of Marticorena and Bergametti (1995) and Alfaro and Gomes (2001). The coupled RegCM3-dust model has been tested for dust storm cases as well as long-term simulations over an Africa-Europe domain by (Zakey et al. 2006).

Initial and boundary conditions. RegCM3 requires initial conditions and time-dependent lateral boundary conditions for the wind components, temperature, surface pressure, and water vapor. In addition, SSTs must be specified over oceans. An interface has been developed to easily port various reanalysis and GCM boundary conditions to the RegCM3 framework. To date, several global reanalysis products and GCMs have provided boundary conditions to RegCM3, including the National Centers for Environmental Prediction (NCEP)-NCAR reanalysis project (NNRP), 40-yr European Centre for Medium-Range Weather Forecasts (ECMWF) 40-yr Re-Analysis (ERA-40), NCAR Community Climate Model Version 3 (CCM3), ECHAM, Hadley Centre Climate Model (HadAM3), and fvGCM. In addition, RegCM3 can be nested (one way) within itself or within other RCMs, including Providing Regional Climates for Impacts Studies (PRECIS; S. Krichak 2005, personal 
communication) and MM5 (M. Ashfaq 2005, unpublished manuscript).

Soil moisture is generally initialized according to the vegetation specification (e.g., desert $=$ dry) (Giorgi and Bates 1989). However, if desired, soil moisture can be initialized according the Climate Prediction Center (CPC) datasets (Huang et al. 1996; Fan and Van den Dool 2004) with a prescribed vertical profile according to Pal and Eltahir (2001) or using soil moisture from the driving model. The land cover is specified using the Global Land Cover Characterization (GLCC) version 2 data provided by the U.S. Geological Survey (USGS) Earth Resources Observation System Data Center (Loveland et al. 2000). As with soil moisture, the soil texture class is generally prescribed according to the vegetation characterization (e.g., desert $=$ sand). Alternatively, an interface exists to interpolate the Food and Agricultural Organization of the United Nations (FAO) soil texture data (Webb et al. 1993) to the RegCM3 grid.

\section{Examples of RegCM applications. RegCM3 has been} run over various regions at grid spacings ranging from 10 to $100 \mathrm{~km}$ and simulation periods from days to decades to study a variety of scientific problems. Some of these applications include future climate change (Diffenbaugh et al. 2005; Gao et al. 2006a; Giorgi et al. 2004b), air quality (F. Meleux, F. Giorgi, and F. Solmon, unpublished manuscript; Solmon et al. 2006), water resources (Pal and Eltahir 2002), extreme events (Pal et al. 2004), agriculture (White et al. 2006), land-cover change (Gao et al. 2006b; Abiodun et al. 2007), and biosphere-atmosphere interactions (Pal and Eltahir 2003). In addition, some preliminarywork has been performed using RegCM3 for seasonal prediction applications (Rauscher et al. 2006, 2007; Seth et al. 2006). This diverse range of applications and regions shows the versatility and portability of the RegCM system.

\section{EXAMPLE CASES FROM TROPICAL} BENCHMARK SIMULATIONS USING

RegCM3. To test the performance of RegCM3, we carried out a series of benchmark simulations over a range of midlatitude and tropical regions. It is outside the purpose of this paper to provide a detailed validation of these simulations. Rather, we limit the present discussion to a brief illustration of the model performance by presenting results from three of the benchmark experiments over tropical domains: Africa, South America, and South Asia (Fig. 1). More detailed analyses of these simulations, as well as the other benchmark experiments, will be presented in papers currently in preparation. We focus here on tropical domains because of the RegCNET emphasis on EDNs. In addition, the RegCM system has already been shown to perform well over midlatitude regions [e.g., Pal et al. (2000) for North America; Giorgi et al. (2004a) for Europe; Steiner et al. (2005); and Gao et al. (2006c) for east Asia]. Apart from the domain locations and sizes, the model configuration for each simulation is identical (including the model parameters). Each domain has a horizontal grid spacing of $50 \mathrm{~km}$ and 18 levels in the vertical. The vertical levels are spaced such that the highest concentration is near the surface. In each simulation, the MIT scheme is used to represent convection and BATS is used to represent the land surface. We stress that using alternative physics options or parameters within a physics option can lead to substantially different and perhaps improved results. For example, Seth et al. (2006) showed that simulations over South America using the Grell convection scheme displayed a large dry bias in the austral summer (December-February; DJF) over the Amazon region that was absent in analogous simulations with the MIT scheme. In addition, while the effects of aerosols are not included in these simulations, they can significantly affect climate over these regions (e.g., Menon et al. 2002; Solmon et al. 2006).

The simulations are $14 \mathrm{yr}$ in length (October 1986-January 2000) and use boundary conditions from ERA-40. We analyze 14-yr climatological averages (1987-2000) of precipitation, surface air temperature, and low-level winds for one season in each region: June-August (JJA) for the West African monsoon system, January-March (JFM) for the South American monsoon system, and June-September (JJAS) for the South Asian monsoon system. These periods encompass the warm and wet seasons over the selected regions. The observations used for comparison with the model results are from the Climatic Research Unit (CRU) land surface temperature and precipitation $0.5^{\circ}$ resolution dataset, from the CPC Merged Analysis of Precipitation (CMAP) $2.5^{\circ}$ resolution dataset for ocean areas, and from the ERA-40 $2.5^{\circ}$ resolution product for low-level (sigma $=0.91$ ) winds and air temperature over oceans. Generally speaking, the RCM solution should agree with the large-scale driving fields, but complex topography can cause some deviations. Such differences provide an example of the added value that is derived from the higher resolution of the RCM simulation. Furthermore, RCM precipitation and surface temperature fields are often expected to deviate from those of the driving fields. 
(a) RegCM3 Topography

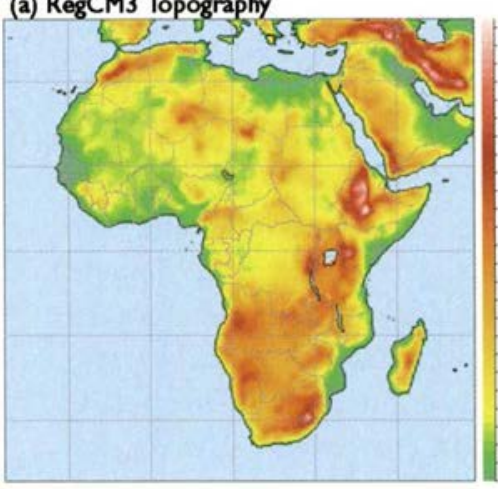

(c) RegCM3 Topography

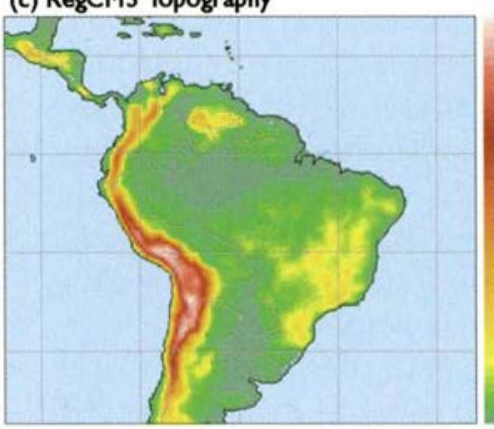

(e) RegCM3 Topography

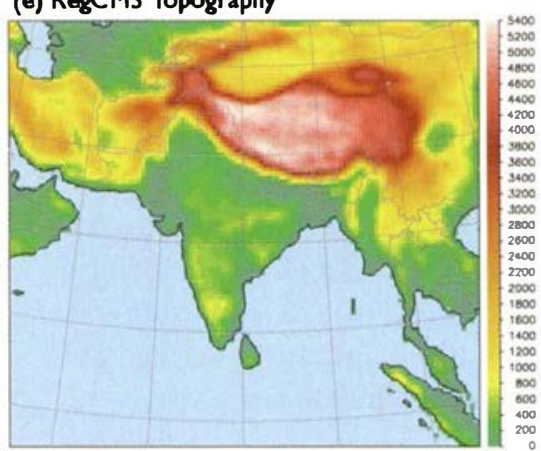

(b) RegCM3 Land Cover

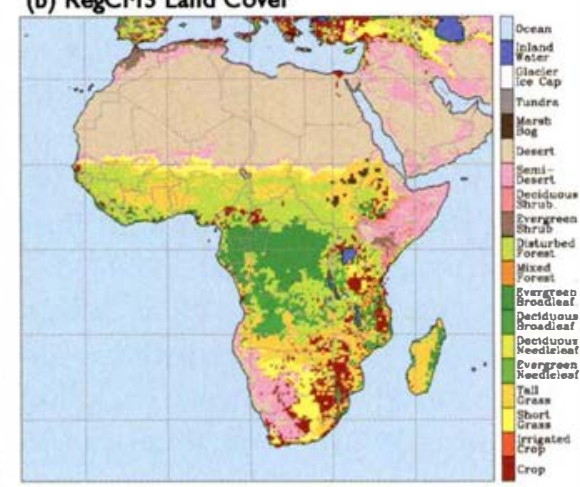

(d) RegCM3 Land Cover

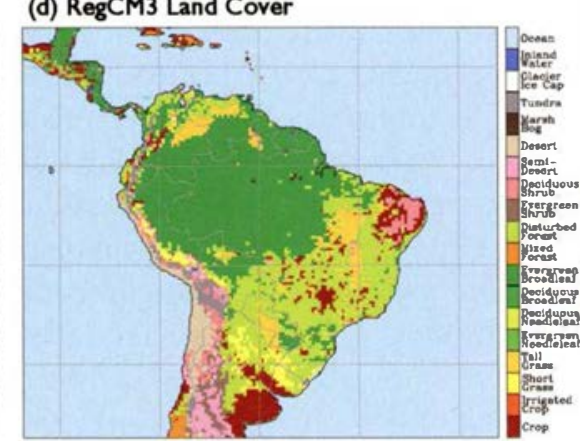

(f) RegCM3 Land Cover

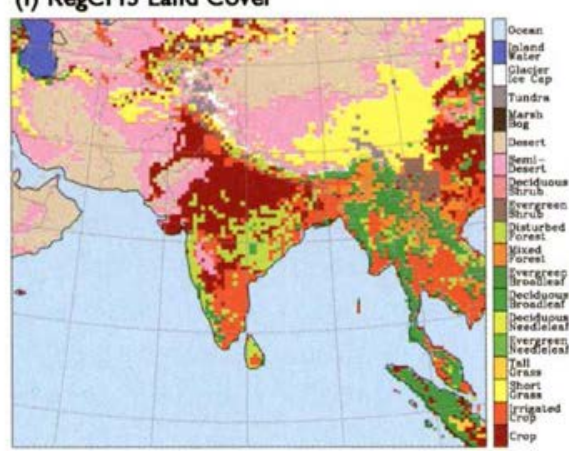

FIG. I. Map of topography and land cover for each domain used in this study. The grid spacing in each domain is $50 \mathrm{~km}$, but the number of grid points and therefore the physical domain size varies for each region. Note that the elevation scale differs for each domain.

West African monsoon climatology. During the northern summer, the West African monsoon provides the region with most of its annual rainfall. A comparison between the simulated and observed precipitation fields shows that RegCM3 performs reasonably well in capturing the general rainfall patterns (Figs. 2a,b). Areas that have little or no precipitation are well located even at some relatively small scales (e.g., Madagascar) with a noticeable exception over the northwestern Sahel region; however, there is a tendency for the model to simulate excessive precipitation over the wettest areas. In addition, the location of the core of the monsoon rainbelt [or inter-tropical discontinuity (ITD)] is simulated a few degrees too far north over West Africa. Preliminary simulations

including the interactions of Saharan dusts show a tendency to reduce this bias by shifting the monsoon belt south and reducing the intensity of the precipitation (F. Solmon 2007, unpublished manuscript).

Direct comparison to other RCM studies over West Africa is difficult, because the domains, years simulated, and seasons presented vary from study to study. Nonetheless, Af iesimama et al. (2006) found that in RegCM3 simulations driven by NNRP version 2 data and using the Grell scheme, the ITD is simulated to the south of its observed location. Similarly, the ITD was located too far south in simulations using a modified version of MM5 (Vizy and Cook 2002). In a 25-yr RCM experiment performed for West Africa using Max Planck Institute for Meteorology Regional Model (REMO), Paeth et al. (2005) reproduced the spatial pattern of annual precipitation, but underestimated total precipitation by up to $25 \%$ over southern West Africa. In contrast, Gallée et al. (2004) found that Modèle Atmosphérique Régional (MAR) overestimated precipitation in August, and like RegCM3, placed the ITD north of its observed position. In addition, the precipitation maxima along the coast near Guinea/Sierra Leone and Cameroon were not well captured in their simulation.

Analysis of the low-level winds shows consistency with ERA-40. Over regions where there is no precipitation, the winds are generally similar to the reanalysis in both magnitude and direction. In the high-convergence regions (i.e., West Africa), the winds tend to be too intense. This is particularly true for the monsoon region, where it can be seen that the intensity of the winds that enter the Guinea coast is too high. Although we are unable to demonstrate 
cause and effect, it appears that the enhancement of the winds and excessive monsoon convection interact with each other. This conclusion is supported by the fact that Vizy and Cook (2002) show the opposite effect; that is, the northward component of the lowlevel flow is weaker than observed and associated with an ITD that is located too far south.

Over the ocean, the sigma 0.91 temperatures correspond well to the ERA- 40 product (Figs. 2c,d). Over land regions, the 2-m temperature patterns agree well with the CRU data. In general, where the model overpredicts (underpredicts) precipitation, there is a tendency to underpredict (overpredict) temperature. An example of this feature can be seen over the core portion of the monsoon belt where the surface temperatures are underestimated by up to $2^{\circ} \mathrm{C}$. Over the Sahara desert areas, the model shows a tendency to overestimate temperature by $1^{\circ}-2^{\circ} \mathrm{C}$. These biases are of a similar magnitude to lowlevel temperature biases observed in other RCM simulations over West Africa (e.g., Gallée et al. 2004). Again, RegCM3 simulations including interactive dusts show a reduction in the surface temperatures over the Sahara (F. Solmon 2007, unpublished manuscript). In addition, preliminary RegCM3 coupled with CLM3 simulations show a reduction in temperature bias, as well, precipitation bias (A. Steiner 2007, unpublished manuscript).

In summary, RegCM3 performs fairly well in simulating the precipitation, low-level/surface temperature, and wind patterns over Africa during JJA. The biases seen in the simulations are similar in magnitude to (or in some cases smaller than) those observed in other RCM studies performed over West Africa. In particular, the main features of the West African monsoon are captured reasonably well, with a tendency for this particular configuration of the model to overpredict the intensity of the monsoon.

South American monsoon system climatology. The Amazon Basin receives the majority of its precipitation during the Southern Hemisphere summer. RegCM3 using the Grell convection scheme (RegCM3/Grell) has had some success in simulating the patterns of precipitation over tropical South America, although it underestimated the magnitudes of both precipitation and temperature (e.g., Rauscher et al. 2006; Fernandez et al. 2006; Seth et al. 2006). This problem was also present in RegCM2.5 (e.g., Qian et al. 2003; Seth and Rojas 2003) and in other RCMs (e.g., Nicolini et al. 2002; Vernekar et al. 2003).

A comparison of our simulation to the CMAP/ CRU data demonstrates that RegCM3 using the MIT scheme performs reasonably well in simulating the (a) CRU/CMAP Precipitation \& ERA40 Winds

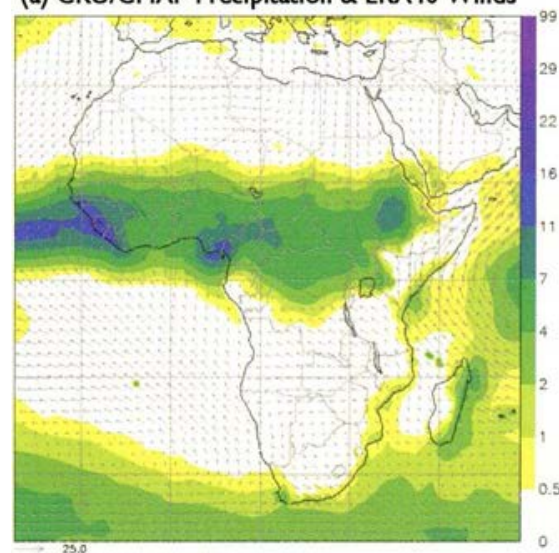

(c) CRU/ERA Temperature

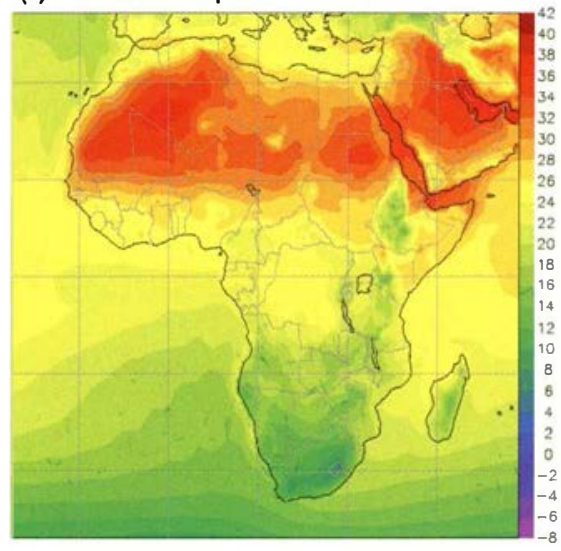

(b) RegCM3 Precipitation \& Winds

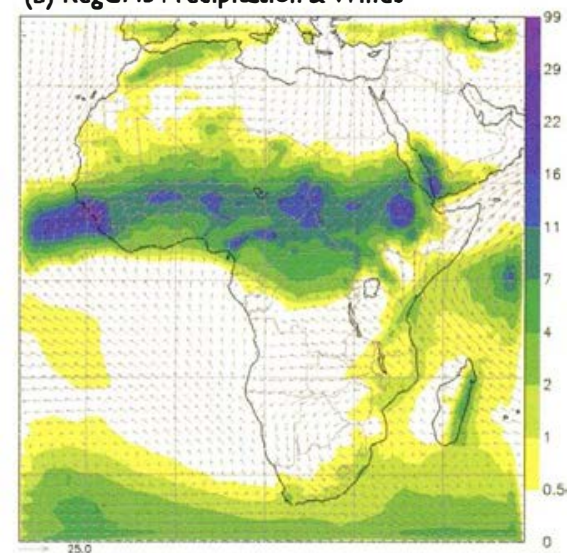

(d) RegCM3 Temperature

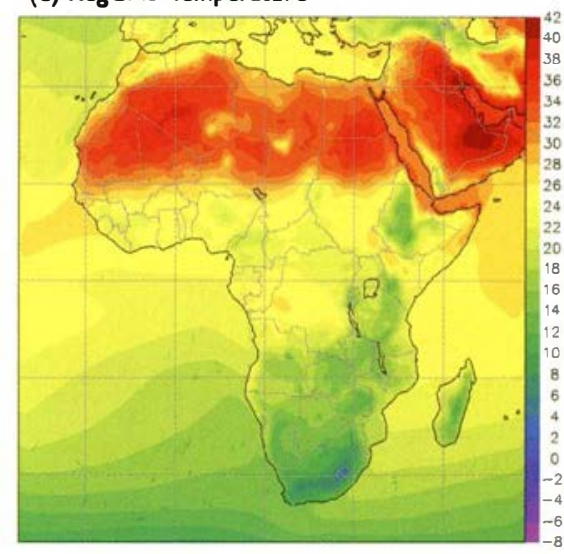

FIG. 2. Maps of sigma 0.91 winds $\left(\mathrm{m} \mathrm{s}^{-1}\right)$, precipitation $\left(\mathrm{mm} \mathrm{day}^{-1}\right)$, and surface temperature $\left({ }^{\circ} \mathrm{C}\right.$ ) for JJA $1987-2000$ over Africa. (a) Validation precipitation and wind. (b) RegCM3 precipitation and wind. (c) Validation temperature. (d) RegCM3 temperature. The validation precipitation data are CRU over land and CMAP over ocean. The validation wind data are ERA40. The validation temperature data are CRU over land and ERA40 over ocean. 
distribution of precipitation over South America and its surrounding oceans during JFM (Figs. 3a,b). For the entire Amazon basin, the simulated precipitation is within $10 \%$ of observations. In addition, the low-level wind patterns are in good agreement with the ERA-40 data. This corrects a tendency for weak northeasterlies observed in the simulations of Seth and Rojas (2003) and Rojas and Seth (2003) using RegCM2.5. The peak in precipitation at the entry region of the monsoon flow (near the mouth of the Amazon River) is accurately captured, as is the peak in the southern Amazon. Furthermore, the relatively dry conditions over northeast Brazil and Colombia are also well simulated.

Over the Andes, RegCM3 reproduces the location of the precipitation peaks, but tends to overpredict precipitation in the steepest topographical slopes. This is a common occurrence in RCM simulations of South America (e.g., Qian et al. 2003; Fernandez et al. 2006; Vernekar et al. 2003; Misra et al. 2002; Seth and Rojas 2003). Recent tests with RegCM3 indicate that this overprediction occurs when the curvature of the model topography is largest (e.g., transition from the ocean to the Andes) and that light topographical smoothing applied in such regions can alleviate the problem. Over the ocean, the location of the Atlantic ITCZ is well

placed, but its primary core is slightly weak. This is likely due to the excessive precipitation simulated at the eastern boundary of the domain over the ITCZ.

Over land, the spatial distribution of surface air temperature is quite accurately reproduced (Figs. 3c,d), in particular the locations of the local minima and maxima. Temperatures in the simulation, however, are underestimated over the Amazon Basin by $1^{\circ}-2^{\circ} \mathrm{C}$ and are overestimated in northern Argentina and Paraguay by the same amount. Over ocean, the sigma 0.91 temperatures are generally well represented, with a slight warm bias (about $1^{\circ} \mathrm{C}$ ) over the Atlantic portion of the ITCZ where precipitation is underestimated.

Overall, the use of the MIT convection scheme leads to improved simulation precipitation, temperature, and low-level wind patterns compared to the RegCM3/Grell configuration of Seth et al. (2006) and to previous versions of the RegCM system. Furthermore, RegCM3 appears to perform better than a suite of four RCMs (including RegCM2.5) evaluated in an intercomparison project over South America (Roads et al. 2003).

South Asia monsoon climatology. Climate models have traditionally had considerable difficulty simulating the characteristics of the

(a) CRU/CMAP Precipitation \& ERA40 Winds

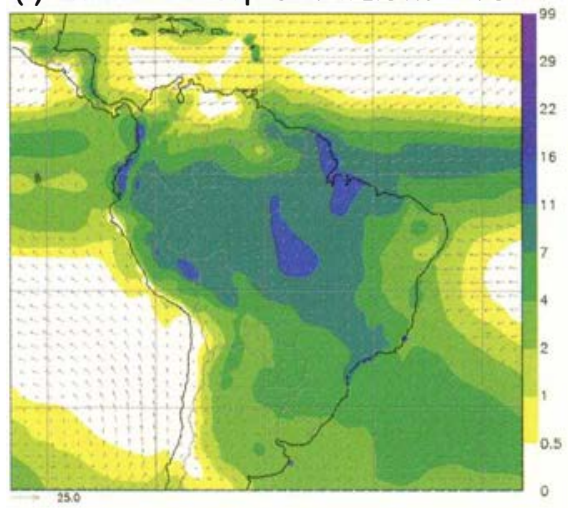

(c) CRU/ERA Temperature

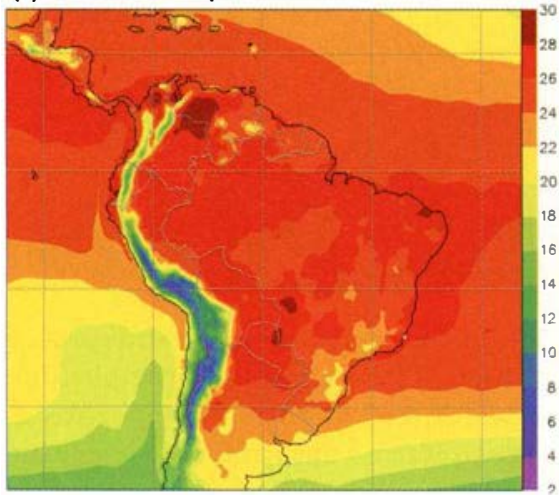

(b) RegCM3 Precipitation \& Winds

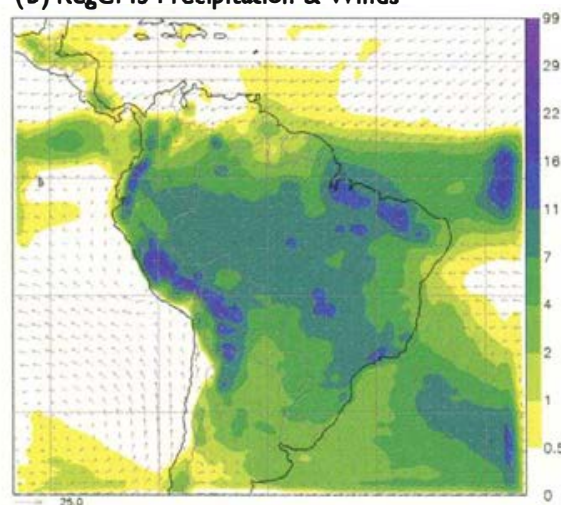

(d) RegCM3 Temperature

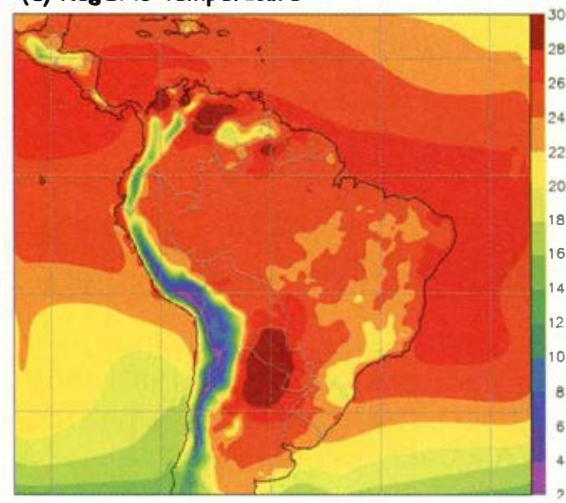

FIG. 3. Same as Fig. 2, but for JFM (1987-2000) over South America.
South Asia monsoon precipitation (Webster et al. 1998). This is likely due in part to the region's complex topography and coastlines, which are typically not well resolved in GCMs. RCMs, however, improve upon the representation of these characteristics (Giorgi et al. 2001). As with the other simulations, the general observed precipitation patterns are fairly well simulated over both land and ocean (Figs. 4a,b). The locations of high precipitation areas over the western Ghats, Nepali upslopes, and Indo-China Peninsula coastal areas are accurately placed. Of particular note, the RegCM3 simulates the peak in central eastern India, though a few degrees to the south. This peak is not captured 
by most GCMs, including most models used in the most recent Intergovernmental Panel on Climate Change (IPCC) report ( . Karmacharya et al. 2006, unpublished manuscript). The direction and magnitude of the low-level flow patterns associated with the monsoon are also accurately simulated, except for an overestimation in the southernflank of the monsoon jet core. It should be noted that the model simulates the rain shadow over southern and central India; however, the overall positive precipitation bias makes it somewhat difficult to distinguish.

Because of the complex nature of the monsoon processes over South Asia, there is little intermodel consistency in the representation of precipitation (e.g., Ramelet al. 2006; Park and Hong 2004; Hassell and Jones 1999; Rao et al. 1994).

The overall qualitative performance of RegCM3 is similar to that of these studies; in some regions, the RegCM3 simulation compares more favorably with observations (e.g., Himalayan upslopes), while in other regions less favorably (e.g., rain shadow over southern India).

The temperature patterns and magnitudes are well simulated, with biases predominantly less than $2^{\circ} \mathrm{C}$ (Figs. $4 \mathrm{c}, \mathrm{d}$ ). In areas where precipitation is overestimated, temperatures are overestimated (e.g., western Ghats). As in the Africa simulation, higher-thanobserved temperatures are simulated in semi-desert and desert regions, particularly over eastern Pakistan. The overall bias is again in line with previous RCM studies over South Asia that include comparisons to surface temperature observations (e.g., Hassell and Jones 1999; Rao et al. 1994).

SUMMARY AND FUTURE PLANS. In this paper, we present the recently inaugurated ICTP Regional Climate Network, or RegCNET, and the newly released ICTP RegCM3. RegCNET is a network aimed at fostering climate research in EDNs (b) RegCM3 Precipitation \& Winds

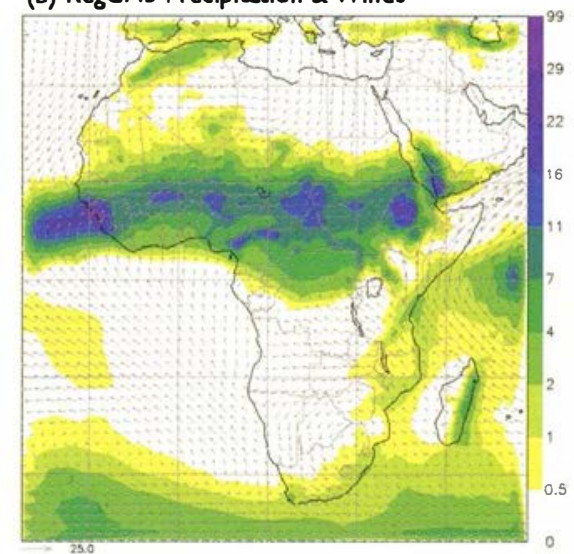

(d) RegCM3 Temperature

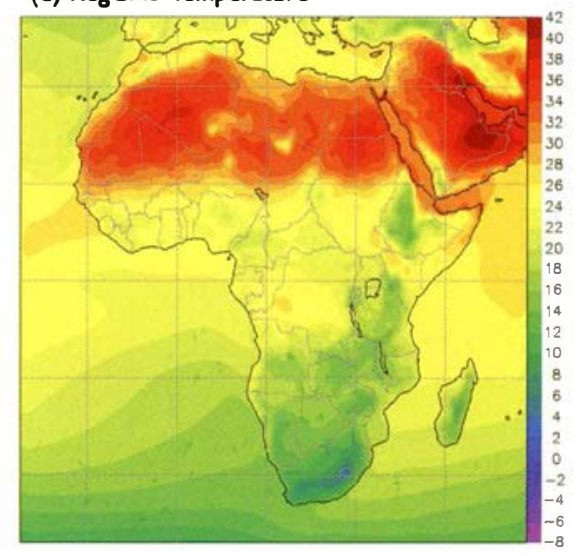

\section{FiG. 4. Same as Fig. 2, but for JJAS (1987-2000) over south Asia.}

by creating south-south and north-south scientific interactions on the topics of regional climate and impacts research and modeling. The success of RegCNET is demonstrated by a rapid growth in interest and participation since its establishment in June 2003. In particular, an especially noteworthy product of RegCNET is a special issue of Theoretical and Applied Climatology (Giorgi et al. 2006), which include 18 papers led mostly by EDN scientists.

The future activities of RegCNET will continue to address the wide variety of locally specific problems faced by EDN scientists, which of ten require specifically designed solutions. Therefore, a primary aim of future RegCNET activities will be to hold more on-site workshops in EDNs in addition to the regular RegCNET workshop series at ICTP. For example, a workshop of this type was held in Botswana in 2006, and another workshop will be conducted in Turkey in 2007.

Another goal is to expand RegCNET research activities, in particular toward the application of climate model output to impact studies of particular interest to EDNs. In this regard, increased focus will be on climate impacts on hydrology and water 
resources, agriculture and food production, and air quality. The primary focus of the 2006 biannual RegCNET workshop was to provide training in the use of RCM and GCM output to drive two hydrological and two crop models.

Funding is crucial to the success of RegCNET, which has already started to generate some signif icant resources for scientists in EDNs. For example, an Asia-Pacific Network for Global Change (APN) project involving institutes in Bangladesh, India, Nepal, and Pakistan was recently awarded for RegCNET-related work. In addition, two Global Change SysTem for Analysis, Research and Training (START) fellowships were awarded to scientists in Ivory Coast, Niger, and Nigeria. At a larger scale, the European Union project Central and Eastern Europe Climate Change Impact and Vulnerability Assessment (CECILIA), which investigates regional climate and impacts over Central and Eastern Europe, originated from RegCNET.

Thus far, f unding for RegCNET activities has relied on the interest and commitment of the participants. It is, however, critical to the growth of RegCNET to pursue funding sources directly for RegCNET. In this regard, there are a number of organizations and programs that aim at promoting climate research in EDNs, such as START, APN, and Assessments of Impacts and Adaptations to Climate Change (AIACC). It is important that RegCNET develops some synergistic interactions with these programs in order to enhance its effectiveness and impact.

Along these lines, we plan to formally establish collaborations between EDN institutes and the ICTP. These institutes would act as hubs for the coordination of RegCNET activities in their regions. This could include the pursuit of funding for collaborative research projects and the provision of infrastructure for high-computation facilities. We are in the initial stages of developing such partnerships with the Global Change Impact Studies Centre (GCISC) in Islamabad, Pakistan, and the Kofi Annan Centre of Excellence in Information and Communication Technology (ICT) (KACE) in Accra, Ghana.

Concerning the RegCM system, we describe a number of important developments and improvements relative to previous versions. In particular, a pointed effort was made to improve the model applicability over tropical regions. The illustrative examples shown here indicate a generally good level of performance within this context. More detailed analyses of these benchmark simulations, along with simulations of climate in additional regions will be presented in future publications.
At present, RegCM3 is a flexible, portable, and user-friendly system that can be applied to a wide range of scientific problems, from process studies to seasonal prediction and climate change applications. Future developments envisioned for the RegCM system include a gradual increase in horizontal resolution af forded by ever-increasing computing power and a move to a nonhydrostatic dynamical core. Higher resolution will also require improvements in the cloud microphysics representation. Consistent with the general trend in climate modeling, we are also working toward a fully coupled regional climate system model framework. In this regard, efforts are underway to couple RegCM3 with the MIT ocean model. In addition, two dynamic land surface schemes [CLM3 and Integrated Biosphere Simulator (IBIS)] will be available upon completion of testing. Within the next few years, RegCM will evolve into a fully coupled nonhydrostatic regional climate modeling system.

It is important to reemphasize that many of the model developments and improvements described in this paper have resulted from interactions and feedback within the ReCNET community. Substantial contributions to model development from the RegCNET community include the implementation, testing, and refinement of the MIT convection scheme, the dust and carbon aerosol modules, and the Zeng ocean flux scheme. These significant advances of RegCM3 provide strong evidence of the mutually advantageous partnerships catalyzed by RegCNET.

The RegCNET Web site is located at users.ictp. it/RegCNET and the RegCNET forum on regional climate, impacts, and associated issues is accessible by e-mail (regcnet@lists.ictp.it). RegCM3 is available online and free of charge for community use at users. ictp.it/RegCNET/model.html.

ACKNOWLEDGMENTS. This paper is dedicated to those that have contributed to the growth of the RegCM system over the past $15+$ years, the members $(250+)$ of RegCNET and ICTP.

\section{REFERENCES}

Abiodun, B. J., J. S. Pal, E. A. Afiesimama, J. W. J. Gutowski, and A. Adedoyin, 2007: Simulation of West African Monsoon using the RegCM3. Part II: Impact of desertification and deforestation, Int. J. Climatol., in press.

Afiesimama, E. A., J. S. Pal, B. J. Abiodun, J. W. J. Gutowski, and A. Adedoyin, 2006: Simulation of 
West African Monsoon using the RegCM3. Part I: Model validation and interannual variability. Theor. Appl. Climatol., 86, 23-37.

Alfaro, S. C., and L. Gomes, 2001: Modeling mineral aerosol production by wind erosion: Emission intensities and aerosol size distribution in source areas. $J$. Geophys. Res., 106, 18 075-18 084.

Anthes, R. A., 1977: A cumulus parameterization scheme utilizing a one-dimensional cloud model. Mon. Wea. Rev., 105, 1423-1438.

- E. Y. Hsie, and Y. H. Kuo, 1987: Description of the Penn State/NCAR Mesoscale Model Version 4 (MM4). NCAR Tech. rep. TN-282+STR, 66 pp.

Briegleb, B. P., 1992: Delta-Eddington approximation for solar radiation in the NCAR Community Climate Model. J. Geophys. Res., 97, 7603-7612.

Deardorff, J. W., 1972: Parameterization of the planetary boundary layer for use in general circulation models. Mon. Wea. Rev., 100, 93-106.

Dickinson, R. E., P. J. Kennedy, A. Henderson-Sellers, P. J. Kennedy, and M. Wilson, 1986: BiosphereAtmosphere Transfer Scheme (BATS) for the NCAR Community Climate Model. NCAR Tech. rep. TN-275+STR, 69 pp.

—, R. M. Errico, F. Giorgi, and G. Bates, 1989: A regional climate model for the western United States. Climate Change, 15, 383-422.

—, A. Henderson-Sellers, and P. J. Kennedy, 1993: Biosphere-Atmosphere Transfer Scheme (BATS) version $1 \mathrm{E}$ as coupled to the NCAR Community Climate Model. NCAR Tech. rep. TN-387+STR, $72 \mathrm{pp}$.

Diffenbaugh, N., J. Pal, R. Trapp, and F. Giorgi, 2005: Fine-scale processes regulate the response of extreme events to global climate change. Proc. Natl. Acad. Sci., 102, $15774-15778$.

Emanuel, K. A., 1991: A scheme for representing cumulus convection in large-scale models. J. Atmos. Sci., 48, 2313-2335.

— , and M. Z. Rothman, 1999: Development and evaluation of a convection scheme for use in climate models. J. Atmos. Sci., 56, 1756-1782.

Fan, Y., and H. Van den Dool, 2004: Climate Prediction Center global monthly soil moisture data set at 0.5 resolution from 1948 to present. J. Geophys. Res., 109, D10102, doi:10.1029/2003JD004345.

Fernandez, J. P. R., S. H. Franchito, and V. B. Rao, 2006: Simulation of the summer circulation over South America by two regional climate models. Part I: Mean climatology. Theor. Appl. Climatol., 86, 247-260.

Francisco, R. V., J. Argete, F. Giorgi, J. S. Pal, X. Bi, and W. J. Gutowski, 2006: Regional model simulation of summer rainfall over the Philippines. Theor. Appl. Climatol., 86, 215-227.

Gallée, H., and Coauthors, 2004: A high-resolution simulation of a West African rainy season using a regional climate model. J. Geophys. Res., 109, L03706, doi:10.1029/2003JD004020.

Gao, X. J., J. S. Pal, and F. Giorgi, 2006a: Projected changes in mean and extreme precipitation over the Mediterranean region from a high-resolution double nested RCM simulation. Geophys. Res. Lett., 33, L03706, doi:10.1029/2005GL024954.

—, D. Zhang, Z. X. Chen, J. S. Pal, and F. Giorgi, 2006b: Land use effects on climate in China as simulated by a regional climate model.Sci. China D: Earth Sci., 50, 628-629.

— , Y. Xu, Z. Zhao, J. S. Pal, and F. Giorgi, 2006c: On the role of resolution and topography in the simulation of East Asia precipitation, Theor. Appl. Climatol., 86, 1-4, doi:10.1007/s00704-005-0214-4.

Giorgi, F., 1991: Sensitivity of simulated summertime precipitation over the western United States to physics parameterizations. Mon. Wea. Rev., 119, 2870-2888.

— regional climate model over complex terrain. Mon. Wea. Rev., 117, 2325-2347.

— section: Regional climate modeling revisited. J. Geophys. Res., 104, 6335-6352.

— , and C. Shields, 1999: Tests of precipitation parameterizations available in latest version of NCAR regional climate model (RegCM) over continental United States. J. Geophys. Res., 104, 6353-6375.

_, M. R. Marinucci, and G. T. Bates, 1993a: Development of a Second-Generation Regional Climate Model (RegCM2). Part I: Boundary-layer and radiative transfer processes. Mon. Wea. Rev., 121, 2794-2813.

,-- - - - and G. De Canio, 1993b: Development of a Second-Generation Regional Climate Model (RegCM2). Part II: Convective processes and assimilation of lateral boundary conditions. Mon. Wea. Rev., 121, 2814-2832.

— , and Coauthors, 2001: Regional Climate Information-Evaluation and Projections. Climate Change 2001; The Scientific Basis, Contribution of Working Group I to the Third Assessment Report of the Intergovernmental Panel on Climate Change (IPCC), J. T. Houghton, Y. Ding, D. J. Griggs, M. Noguer, P. J. van der Linden, and D. Xiaoxu, Eds., Cambridge University Press, 583-638.

- , X. Bi, and Y. Qian, 2003a: Indirect vs. direct effects of anthropogenic sulfate on the climate of 
East Asia as simulated with a regional coupled climate-chemistry/aerosol model. Climatic Change, 58, 345-376.

_, R. Francisco, and J. S. Pal, 2003b: Effects of a subgrid-scale topography and land use scheme on the simulation of surface climate and hydrology. Part I: Effects of temperature and water vapor disaggregation. J. Hydrometeor., 4, 317-333.

- X. Bi, and J. S. Pal, 2004a: Mean, interannual variability and trends in a regional climate experiment over Europe. I: Present day climate (1960-1990). Climate Dyn., 22, 733-756.

- , — and - 2004b: Mean, interannual variability and trends in a regional climate experiment over Europe. II: Future climate (2070-2100). Climate Dyn., 23, 839-858.

,,,--- N. Elguindi, F. Solmon, and L. Sloan, 2006: The Regional Climate Network (RegCNET): Introduction to the special issue. Theor. Appl. Climatol., 86, 1-4.

Grell, G. A., 1993: Prognostic evaluation of assumptions used by cumulus parameterizations. Mon. Wea. Rev., 121, 764-787.

—, J. Dudhia, and D. R. Stauffer, 1994: Description of the fifth generation Penn State/NCAR Mesoscale Model (MM5). NCAR Tech. rep. TN-398+STR, 121 pp.

Hassell, D., and R. Jones, 1999: Simulating climatic change of the southern Asian monsoon using a nested regional climate model (HadRM2). Hadley Centre Tech. Rep. HCTN 8, 46 pp.

Holtslag, A. A. M., E. I. F. de Bruijn, and H. L. Pan, 1990: A high resolution air mass transformation model for short-range weather forecasting. Mon. Wea. Rev., 118, 1561-1575.

Hostetler, S. W., and P. J. Bartlen, 1990: Simulation of lake evaporation with applicaiton to modeling lakelevel variations at Harney-Malheur Lake, Oregon. Water Resour. Res., 26, 2603-2612.

Hsie, E. Y., R. A. Anthes, and D. Keyser, 1984: Numerical simulation of frontogenesis in a moist atmosphere. J. Atmos. Sci., 41, 2581-2594.

Huang, J., H. M. Van den Dool, and K. Georgakakos, 1996: Analysis of model-calculated soil moisture over the U.S. (1931-93) and application in long-range temperature forecasts. J. Climate, $\mathbf{9}$, 1350-1362.

Huntingford, C., and J. H. C. Gash, 2005: Climate equity for all. Science, 309, 1789-1789.

Kiel, J. T., R. J. Wolski, B. P. Briegleb, and V. Ramanathan, 1987: Documentation of radiation and cloud routines in the NCAR Community Climate Model (CCM1). NCAR Tech. rep. TN-288+1A, 109 pp.
—, J. J. Hack, G. B. Bonan, B. A. Boville, B. P. Briegleb, D. L. Williamson, and P. J. Rasch, 1996: Description of the NCAR Community Climate Model (CCM3). NCAR Tech. Rep. TN-420+STR, 152 pp.

Loveland, T. R., B. Reed, D. O. Ohlen, J. Zhu, L. Yang, and J. Merchant, 2000: Development of a global land cover characteristics database and IGBP DISCover from 1-km AVHRR data. Int. J. Remote Sens., 21, 1303-1330.

Marticorena, B., and G. Bergametti, 1995: Modeling the atmospheric dust cycle: 1. Design of a soilderived dust emission scheme. J. Geophys. Res., 100, $16415-16430$.

Menon, S., J. Hansen, L. Nazarenko, and Y. F. Luo, 2002: Climate effects of black carbon aerosols in China and India. Science, 297, 2250-2253.

Misra, V., P. A. Dirmeyer, and B. P. Kirtman, 2002: Regional simulation of interannual variability over South America. J. Geophys. Res., 107, 8036, doi: 10.1029/2001JD900216.

Nakicenovic, N., and Coauthors, 2001: Emission Scenarios, A Special Report of Working Group III of the Intergovernmental Panel on Climate Change. Cambridge University Press, 599 pp.

Nicolini, M., P. Salio, J. J. Katzfey, J. L. McGregor, and A. C. Saulo, 2002: January and July regional climate simulation over South America. J. Geophys. Res., 107, 4637, doi:10.1029/2001JD000736.

Paeth, H., K. Born, R. Podzun, and D. Jacob, 2005: Regional dynamical downscaling over West Africa: Model evaluation and comparison of wet and dry years. Meteor. Z, 14, 349-367.

Pal, J. S., and E. A. B. Eltahir, 2001: Pathways relating soil moisture conditions to future summer rainfall within a model of the land-atmosphere system. J. Climate, 14, 1227-1242.

— and — 2002: Teleconnections of soil moisture and rainfall during the 1993 Midwest Summer Flood. Geophys. Res. Lett., 29, 1865, doi:10.1029/ 2002 GL014815.

—, and —, 2003: A feedback mechanism between soil moisture distribution and storm tracks. Quart. J. Roy. Meteor. Soc., 129, 2279-2297.

—, E. E. Small, and E. A. B. Eltahir, 2000: Simulation of regional scale water and energybudgets: Influence of a new moist physics scheme within RegCM. J. Geophys. Res., 105, 29 579-29 594.

—, F. Giorgi, and X. Bi, 2004: Consistency of recent European summer precipitation trends and extremes with future regional climate projections. Geophys. Res. Lett., 31, L13202, doi:10.1029/2004GL019836.

Park, S., and S. Hong, 2004: The role of surface boundary forcing over South Asia in the Indian summer 
monsoon circulation: A regional climate model sensitivity study. Geophys. Res. Lett., 31, L12112, doi:10.1029/2004GL019729.

Qian, J.-H., A. Seth, and S. Zebiak, 2003: Reinitialized versus continuous simulations for regional climate downscaling. Mon. Wea. Rev., 131, 2857-2874.

Qian, Y., and F. Giorgi, 1999: Interactive coupling of regional climate and sulfate aerosol model over eastern Asia. J. Geophys. Res., 104, 6477-6500.

— _ - Y. Huang, W. L. Chameides, and C. Luo, 2001: Simulation of anthropogenic sulf ur over East Asia with a regional coupled chemistry-climate model. Tellus, 53B, 171-191.

Ramel, R., H. Gallée, and C. Messager, 2006: On the northward shift of the West African monsoon. Climate Dyn., 26, 429-440.

Rao, D. B., K. Ashok, and T. Yamagata, 1994: A numerical simulation study of the Indian summer monsoon of 1994 using NCAR MM5. J. Meteor. Soc. Japan, 82, 1755-1775.

Rauscher, S. A., A. Seth, J.-H. Qian, and S. J. Camargo, 2006: Regional climate model domain choice in the tropics based on process considerations. Theor. Appl. Climatol., 86, 229-246.

— , - B. Liebmann, J.-H. Qian, and S. J. Carmargo, 2007: Regional climate model-simulated timing and character of seasonal rains in South America. Mon. Wea. Rev., 135, 2642-2657.

Roads, J., and Coauthors, 2003: The IRI/ARCs Regional Model Intercomparison over South America. J. Geophys. Res., 108, 4425, doi:10.1029/ 2002JD003201.

Rojas, M., and A. Seth, 2003: Simulation and sensitivity in nested model for South America. Part II: GCM boundary forcing. J. Climate, 15, 2437-2453.

Seth, A., and M. Rojas, 2003: Simulation and sensitivity in a nested modeling system for South America. Part I: Reanalyses boundary forcing. J. Climate, 16, 2437-2453.

—, S. A. Rauscher, S. J. Carmago, J.-H. Qian, and J. S. Pal, 2006: RegCM3 regional climatologies using reanalysis and ECHAM global model driving fields. Climate Dyn., 28, 461-480.
Solmon, F., F. Giorgi, and C. Liousse, 2006: Aerosol modeling for regional climate studies: Application to anthropogenic particles and evaluation over a European/African domain. Tellus, 58, 51-72.

Steiner, A. L., J. S. Pal, F. Giorgi, R. E. Dickinson, and W. L. Chameides, 2005: The coupling of the Common Land Model (CLM0) to a regional climate model. Theor. Appl. Climatol., 82, 225-243.

Vernekar, A. D., B. P. Kirtman, and M. J. Fenessy, 2003: Low-level jets and their effects on the South American summer climate as simulated by the NCEP Eta model. J. Climate, 16, 297-311.

Vizy, E., and K. Cook, 2002: Development and application of a mesoscale climate model for the tropics: Influence of sea surface temperature anomalies on the West African monsoon. J. Geophys. Res., 107, 4023, doi:10.1029/2001JD000686.

Webb, R. S., C. E. Rosenzweig, and E. R. Levine, 1993: Specif ying land surface characteristics in general circulation models soil profile data set and derived water holding capacities. Global Biogeochem. Cycles, 7, 97-108.

Webster, P. J., V. O. Magana, T. N. Palmer, J. Shukla, R. A. Tomas, M. Yanai, and T. Yasunari, 1998: Monsoons: Processses, predictability, and the prospects for prediction. J. Geophys. Res., 103, 14 451-14 510.

White, M., N. Diffenbaugh, G. Jones, J. Pal, and F. Giorgi, 2006: Increased heat stress in the 21st century reduces and shifts premium wine production in the United States. Proc. Natl. Acad. Sci., 103, doi:10.1073/pnas.0603230103.

Zakey, A., F. Solmon, and F. Girogi, 2006: Development and testing of a desert dust module in a regional climate model. Atmos. Chem. Phys., 6, 4687-4704.

Zeng, X., M. Zhao, and R. E. Dickinson, 1998: Intercomparison of bulk aerodynamic algorithms for the computation of sea surface fluxes using TOGA COARE and TAO data. J. Climate, 11, 2628-2644.

Zhang, G. J., and N. A. McFarlane, 1995: Sensitivity of climate simulations to the parameterization of cumulus convection in the Canadian Climate Centre general circulation model. Atmos. Ocean, 33, 407-446. 